\title{
$\mathrm{LCD}$ 디스플레이 프레임 조립 공정 최적화 연구 \\ 윤철호 ${ }^{*}$ \\ ${ }^{1}$ 선문대학교 산업경영공학과
}

\section{A Study for Optimizing LCD Display Frame Assembly Process}

\author{
Cheol-ho Yoon ${ }^{1 *}$ \\ ${ }^{1}$ Dept. of Industrial \& Management Engineering, Sunmoon University
}

요 약 본 연구에서는 LCD 디스플레이 프레임의 제품 원가를 절감하기 위해 조립공정의 최적화에 대해 연구하였 다. 첫째로 OTRS를 이용하여 조립공정의 효율성을 분석하였고, 둘째로 낮은 가격의 원자재 코일을 대상으로 정해진 신뢰성 기준에 합격할 수 있는 프레임을 생산할 수 있는지 평가하였다. 연구 결과, 프레임 조립공정은 자동화가 상당 수준 진척되었기 때문에 높은 생산성이 유지되고 있다는 것을 알 수 있었고, 동시에 정해진 기준에 합격할 수 있는 프레임을 확보할 수 있는 가능성이 제시되었다.

\begin{abstract}
This paper studies the assembly process of LCD display frames to reduce product cost. First of all, OTRS and time study methodology were performed to analyze the efficiency of the assembly process. Next, various types of frame materials are evaluated whether they pass the reliability criteria or not. As a result, it is found that the productivity of LCD display assembly process maintains prefer level and some frame materials have an opportunity to reach the reliability criteria.
\end{abstract}

Key Words : LCD Display, Assembly Process, Productivity, Time Study, OTRS(Operation Time Research Software)

\section{1. 연구 배경}

2006년 이후 LCD 디스플레이의 지속적인 판매가격 하락으로 인하여 LCD 관련 기업들의 채산성은 극도로 낮아지고 있다[1]. 이에 따라 관련 기업들은 해마다 제품 의 원가를 평균적으로 $20-30 \%$ 지속적으로 절감시켜 나 가야 하는 상황에 처하게 되었다. 원가 절감을 달성하지 못할 경우 국내 기업들은 향후 2-3년 이내에 현재의 위치 를 지키지 못하는 커다란 위기에 직면할 수도 있다. 따라 서 기업들은 해당 제품의 제품원가를 낮추기 위해 기업 의 사활을 건 노력을 경주하고 있으며 LCD 디스플레이 프레임을 제작하는 본 기업에 있어서도 예외는 아니다.

디스플레이 프레임의 경우, 제품 원가의 약 $70 \%$ 정도 가 프레임 원자재 코일이 차지한다. 따라서 프레임 원자 재 코일 구매 비용을 낮추는 것이 대단히 시급하고 중요
하다. 이를 해결하기 위해서는 사용하는 원자재 코일보 다 저렴한 코일을 구매하는 것이 가장 확실한 해결책이 되는데 문제는 단가가 낮은 원자재 코일을 조달하여 프 레임을 제조할 경우, 정해진 품질규격인 신뢰성 기준을 맞추기가 어려워 무작정 낮은 가격의 원자재 코일을 구 매하여 사용하기에 한계가 있다.

본 연구에서는 제품의 원가를 절감하기 위해 첫째로 조립공정의 생산성을 높이기 위해 조립공정의 효율성을 분석한다. 둘째로 낮은 가격의 원자재 코일을 대상으로 정해진 신뢰성 기준에 합격할 수 있는 프레임을 생산할 수 있는지 평가한다. 이를 토대로 $\mathrm{LCD}$ 조립공정의 최적 화 방안을 모색하고자 한다.

본 논문은 충남 디스플레이 $\mathrm{R} \& \mathrm{D}$ 클러스터 사업단 연구과제로 수행되었음.

*교신저자 : 윤철호(yoonch@sunmoon.ac.kr) 


\section{2. 연구 방법}

\section{1 개요}

첫째로, $\mathrm{LCD}$ 디스플레이 프레임 조립공정의 효율성을 분석하여 공정을 최적화하기 위한 방법은 다음과 같다.

- OTRS (Operation Time Research Software)를 이용한 $\mathrm{LCD}$ 디스플레이 프레임

조립공정의 공정별 표준시간, 낭비 공정 분석

둘째로, 낮은 가격의 원자재 코일을 대상으로 정해진 신뢰성 기준에 합격할 수 있는 프레임을 생산할 수 있는 지 평가하기 위한 방법은 다음과 같다.

- 국내외에서 조달 가능한 코일 대체 후보군 설정

- 복수의 대체품에 대한 신뢰성을 분석하기 위한 성분 분석, 유해 물질분석 및 염수분무 시험

- 복수의 대체품에 대한 일반 시험 및 내구성 시험

신뢰성 시험, 일반 시험 및 내구성 시험에 대한 각각의 방법에 대해서는 3.2에서 설명하기로 한다.

\section{2 공정개요}

본 연구에서 대상으로 하고 있는 LCD 디스플레이 프 레임의 조립공정은 크게 원자재코일의 절단 공정, 성형 공정, 세척공정, 건조공정 그리고 검사공정으로 구성되어 있다. 절단에서 건조까지의 공정은 주로 기계 설비 위주 로 구성되어 있으며 작업자는 전체적인 공정의 흐름 관 리와 검사 공정을 담당한다. 전체적인 공정의 구성은 그 림 1 과 같다.

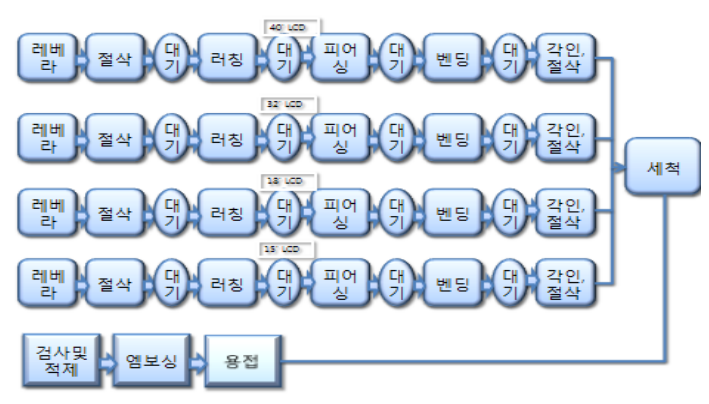

[그림 1] LCD 디스플레이 프레임 조립공정도

\section{3. 연구 결과}

\subsection{LCD 디스플레이 프레임 조립공정 효율 성 분석}

$\mathrm{LCD}$ 디스플레이 프레임 조립공정에 대한 최적화를 위해 먼저 기존에 생산하고 있는 해당 조립공정에 대해 OTRS를 이용하여 공정분석을 실시하였다. 여기서 OTRS란 공정분석을 위한 표준시간을 측정하고 작업자 의 작업동작을 분석하기 위해 개발된 일종의 동작분석용 소프트웨어이다. 처음에 일본에서 개발된 이 소프트웨어 는 수년전 국내에 처음 도입된 이후 여러 제조 기업에서 공정분석을 위한 도구로 사용되고 있다. 이 소프트웨어는 공정과 작업자를 촬영한 비디오 화면을 각 프레임별로 구분하여 각 작업자의 작업동작 및 공정의 요소별 표준 시간을 측정하기에 편리하게 개발되어 기존에 수작업에 의존하던 공정분석을 보다 효율적으로 할 수 있게 도움 을 주기 위한 것이다[5].

공정분석을 위해 해당공정에 대해 담당 직원들과 협의 를 통해 대상 공정을 선정하였으며 대상 공정에 대해 안 정적으로 작업이 수행될 것으로 기대되는 요일을 택해 주 1 회 4주에 걸쳐 반복하여 비디오 촬영을 실시하였다. 해당공정에 대한 데이터는 OTRS를 이용하여 분석하였 으며 각 공정별로 표준요소작업을 정의하고 각각의 요소 작업에 대해 표준시간을 측정하였다. 표준작업시간을 측 정하기 위해 여유율은 현 공정이 많은 부분이 자동화되 어 있기 때문에 검사공정을 제외하고는 $5 \%$ 를 적용하기 로 하였다.

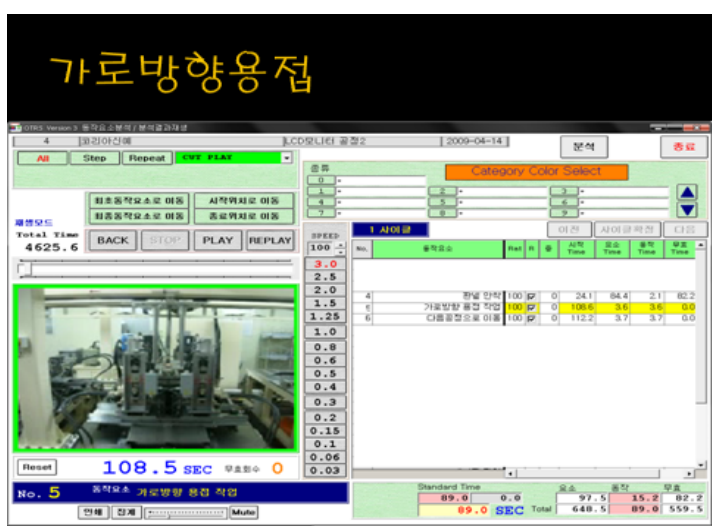

[그림 2] LCD패널 외형절삭 공정 OTRS 분석 화면

그림 2 는 $\mathrm{LCD}$ 디스플레이 프레임 조립공정에 대해 $\mathrm{OTRS}$ 를 이용해 픽업한 화면을 예시한 것이다. 또한 OTRS ( Operation Time Research Software)를 이용하여 각 공정별 표준요소작업에 대해 표준시간을 측정한 결과 는 그림 3 과 같다. 


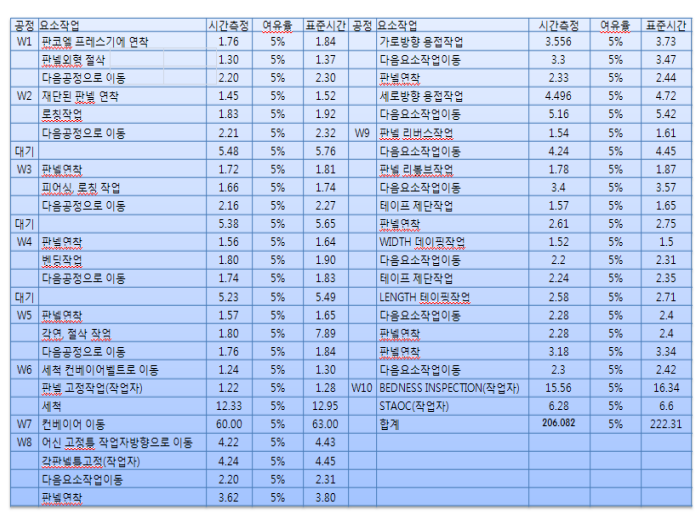

[그림 3] LCD 디스플레이 프레임 조립공정별 표준작업시 간

OTRS를 이용하여 데이터를 분석한 결과 원재료 코일 의 투입에서 세척 공정까지의 tact 타임은 1초이며 이는 공정 설계시 의도한대로 작업이 진행되고 있다는 것을 확인시켜 주었다. 세척 이후의 검사 공정의 tact 타임은 평균 1.8 초 표준편차 0.75 로 공정의 편차가 매우 심한 것 을 알 수 있다. 이는 자동화 생산 라인을 통해 진행되고 있는 디스플레이 프레임의 생산이 검사공정 이후에서 지 체 또는 임의의 작업이 이루어지고 있다는 것을 극단적 으로 보여준다.

\section{2 원자재 코일 신뢰성 분석}

원자재 코일의 신뢰성을 분석하기 위한 검사로는 크게 2 가지 방법을 이용하였다. 첫째는 신뢰성 검사이다. 신뢰 성 검사로는 성분분석, 유해 물질분석 및 염수분무시험의 3 가지를 이용하였다. 둘째로는 일반시험과 내구성시험이 다. 일반시험이란 길이, 높이, 각도 등과 관련한 규격으로 서 정해진 50 개 항목에 대해 측정하고 이를 평가하는 것 이다. 내구성시험이란 디스플레이 프레임의 정해진 위치 에 대한 torque시험을 말한다. 코일 원자재 강판은 프레 싱 공정에 의해 성형이 이루어지는데 이때 직각으로 성 형된 부분의 강도가 약해지는 경우가 있다. 따라서 미리 정해진 디스플레이 프레임의 8 개소에 대해 torque 측정 게이지를 이용하여 torque 값을 구한다.

디스플레이 프레임용 코일 원자재로는 크게 A계열과 $\mathrm{B}$ 계열로 구분하고 있다. 세계적으로 니켈, 크롬의 원자재 가격 상승으로 인해 $\mathrm{A}$ 계열의 코일 원자재의 가격이 큰 폭으로 인상되고 있는 실정이다. 향후 $\mathrm{B}$ 계열에 대해서는 제품가격을 현재의 $\mathrm{A}$ 계열보다 $20-30 \%$ 저렴하게 공급할 예정으로 알려져 있다. 따라서 $\mathrm{B}$ 계열의 제품이 안정적인 가격으로 공급되기 전까지는 이를 대신할 대체 원자재 코일을 선정하는 것이 필요하다. 이를 위해 현재 사용하
고 있는 원자재코일을 대체할 후보군으로서 첫째, 국내외 에서 생산되며 둘째, 가격 면에서 경쟁력이 있는 코일을 대상으로 전부 7 개의 제품을 후보군으로 선정하였다. 7 개 후보군은 각각 $\mathrm{A}, \mathrm{B}, \mathrm{C}, \mathrm{D}, \mathrm{E}, \mathrm{F}, \mathrm{G}$ 로 명명하였다.

\subsection{1 신뢰성 검사}

먼저 성분분석으로서 전부 9 개 항목 $(\mathrm{C}, \mathrm{Si}, \mathrm{Mn}, \mathrm{P}, \mathrm{S}$, $\mathrm{Ni}, \mathrm{Cr}, \mathrm{Mo}$, 경도 )에 대해 분석하였다. 분석은 한국화학 시험연구원에 의뢰하였다. 유해물질 분석으로서 26 개 항 목을 대상으로 하였으며 ( $\mathrm{Pb}, \mathrm{Cd}$ 등) 유해물질 분석 역 시 한국화학시험연구원에 의뢰하였다. 염수분무실험이란 염수분무를 실시한 후 72 시간 및 120 시간 경과 후 백청, 적청의 발생 유무를 시험하는 것으로서 $\mathrm{A}$ 사에 분석을 의 뢰하였다. 이상의 3 가지 신뢰성 검사를 실시한 결과, $\mathrm{A}$, $\mathrm{F}, \mathrm{G}$ 의 3제품이 기준에 미치지 못하여 탈락하였다.

\subsection{2 내구성 검사}

먼저 일반 내구성 검사를 위해 길이, 높이 규격 및 각 도 등에 대해 측정하였다. 4 개 후보군에 대해 전부 50 개 항목, 10 회 반복하여 측정하였는데 그 결과 $\mathrm{B}, \mathrm{C}, \mathrm{D}$ 후보 는 검사 기준을 만족하였고 $\mathrm{E}$ 후보만 약간의 사소한 규격 의 결함이 있었다. 따라서 일반 내구성 검사만으로 $\mathrm{E}$ 후보 를 불합격시키는 것은 보류하기로 하였으며 $\mathrm{B}, \mathrm{C}, \mathrm{D}, \mathrm{E}$ 전부에 대해 torque시험을 실시하기로 하였다. 디스플레 이 프레임의 torque값의 내구성을 검사하기 위해 4 개의 후보군, 8 개의 위치에 대해 10 회 반복하여 측정하였다. 그림 4는 4개 후보군에 대한 측정결과이다.

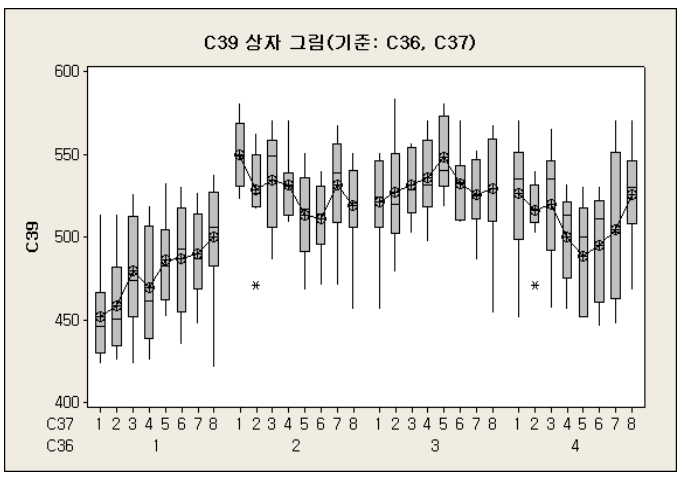

[그림 4] 후보군별 8개소별 torque 측정치

이 데이터를 $\mathrm{A}$ 요인을 디스플레이 프레임 후보군, B요 인을 8 개 위치군으로 2 원 분산분석법에 의해 통계처리를 한 결과 디스플레이 프레임 후보군에 $1 \%$ 수준의 유의한 차이가 있었다. 즉 4 개 후보 중 $\mathrm{B}$ 와 $\mathrm{E}$ 후보는 기준으로 
정해진 torque 값의 수준에 미치지 못하는 부분이 많은 경우를 확인할 수 있는데 따라서 $\mathrm{B}$ 와 $\mathrm{E}$ 후보는 탈락하 고 $\mathrm{C}$ 와 $\mathrm{D}$ 후보가 내구성 검사를 통과하였다.

\section{4. 토의 및 결론}

본 연구에서는 LCD 디스플레이 프레임의 제품 원가 를 절감하기 위해 첫째로 조립공정의 생산성을 높이기 위한 조립공정의 효율성을 분석하였고, 둘째로 낮은 가격 의 원자재 코일을 대상으로 정해진 신뢰성 기준에 합격 할 수 있는 프레임을 생산할 수 있는지 평가하였다. LCD 를 포함한 제조 공정에서의 생산성이나 신뢰성을 개선하 기 위해 많은 연구가 수행되고 있다.[2-4] 본 연구에서는 다음의 두 가지를 연구방법론으로 이용하기로 하였다.

먼저 조립공정에 대한 생산성을 평가하기 위해 OTRS 를 이용하여 공정에 대한 데이터를 수집하고 이를 분석 한 결과 세척 이후의 검사 공정의 편차가 매우 큰 것을 알 수 있었다. 이는 이미 설비투자를 통해 확보한 생산능 력을 유지하면서 상황에 따라 크게 변하는 수요의 변동 을 검사공정에 투입하는 작업자의 수준을 적절히 조절함 으로서 대처하는 것에 기인한다고 보인다. 따라서 현재의 수요 수준이라면 지금의 검사공정의 편차는 받아들일 수 있는 범위 내에 있다고 여겨진다. 그러나 경기가 좋아지 고 수요가 증가하게 되면 기존의 검사 공정에 대한 적절 한 조치가 시급하다. 이는 라인 밸런싱이나 검사공정에 대한 추가설비확보에 의해 가능하다고 판단된다.

다음으로 낮은 가격의 원자재 코일을 대상으로 정해진 신뢰성 기준에 합격할 수 있는 프레임을 찾아보기 위해 국내외에서 조달 가능한 코일 대

체 후보군을 설정하여 성분분석, 유해 물질분석 및 염 수분무 시험을 실시하였으며 동시에 일반 시험 및 내구 성 시험인 torque 시험을 실시하였다. 그 결과 본 연구에 서 수행한 수준의 평가 방법론에 의해서도 어느 정도 대 체품을 평가하는 것이 가능하다는 것을 확인하였다. 물론 제품 생산과 직접적으로 연계시키기 위해서는 보다 정밀 하고 체계적인 평가 기법이 수반되어야 하며 이는 향후 의 연구 과제로 생각된다.

\section{참고문헌}

[1] 박성배, "반도체, $\mathrm{LCD}$ 산업의 경쟁 현황과 시사점", SERI 경제 포커스, 169호, 2007.

[2] 박순옥, 양해술, “전자기기용 소프트웨어의 신뢰성 평
가기법‘, 한국산학기술학회논문지, Vol. 8, No. 4, pp.758-767, 2009.

[3] 박형근, 이승대, 김선엽, "TFT-LCD 채널 검사 자동 화를 위한 원격 모니터링 시스템 개발', 한국산학기 술학회논문지, Vol. 8, No. 3, pp.483-487, 2007.

[4] 윤철호 외, “디지털 도어록 혼류 공정 최적화 설계를 위한 컴퓨터 시뮬레이션 연구”, 한국산학기술학회논 문지, Vol. 10, No. 7, pp.1439-1445, 2009.

[5] M. E. Mundel, D. Danner, Motion and Time Study, Prentice Hall, 7th Ed. 1994.

\section{윤 철 호(Cheol-Ho Yoon)}

[정회원]

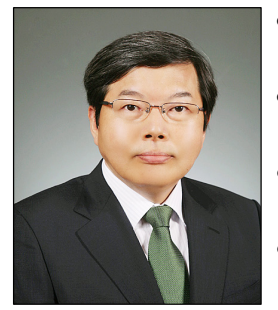

- 1979년 2월 : 한양대학교 자원공 학과 (공학사)

- 1985년 3월 : 동경공대 산업공 학과 (공학석사)

- 1988년 3월 : 동경공대 산업공 학과 (공학박사)

- 1988년 3월 1994년 2월 : 한 국전산원 책임연구원

- 1994년 3월 현재 : 선문대학교 산업경영공학과 교수

<관심분야>

인간공학, 작업관리, 공정분석, 6시그마, 사용자인터페이스 